\title{
Characterization of a circular plasmid from the yeast Kluyveromyces waltii
}

\author{
Xin J. Chen, ${ }^{2}$ Yu S. Cong, ${ }^{1}$ Micheline Wesolowski-Louvel, ${ }^{1}{ }^{\mathrm{YU}} \mathrm{Y} . \mathrm{LI}^{2}$ and \\ HIROSHI FUKUHARA ${ }^{1 *}$ \\ ${ }^{1}$ Institut Curie, Section de Biologie, Bâtiment 110, Centre Universitaire, 91405 Orsay, France \\ ${ }^{2}$ Institute of Genetics, Fudan University, Shanghai 200433, People's Republic of China
}

(Received 14 June 1991; revised 14 August 1991; accepted 7 October 1991)

\begin{abstract}
A new plasmid was found in the yeast Kluyveromyces waltii. This high-copy-number plasmid, named pKW1, is a double-stranded circular DNA plasmid of $5619 \mathrm{bp}$. It has several features characteristic of the $2 \mu$-type plasmids: presence of two inverted repeats and four open reading frames, as well as the interconversion of two isomeric forms. However, the nucleotide sequence shows little homology with known yeast plasmids. An $A R S$ function was localized within a segment of 545 bp near one of the inverted repeats. Chimeric plasmids carrying this segment efficiently transformed $K$. waltii. A strain of $K$. waltii cured of the plasmid (cir ${ }^{\circ}$ ) was also obtained. In the pKW1 sequence, a functionally neutral region was found at which foreign DNA can be inserted with little effect on plasmid stability. Such constructions carrying the full sequence of $\mathrm{pKW} 1$ replicated autonomously in a $\mathrm{cir}^{\circ}$ host and were particularly stable. pKW1-derived full-sequence plasmids also transformed $K$. thermotolerans, but not $K$. lactis.
\end{abstract}

\section{Introduction}

Several circular plasmids resembling the $2 \mu$ plasmid of Saccharomyces cerevisiae have been described: pSR1, pSB3 and pSB4 from Zygosaccharomyces rouxii (Toh-e et al., 1982, 1984), pSB1 and pSB2 from $Z$. bailii (Toh-e $e t$ al., 1984), pSMl from $Z$. fermentatii (Utatsu et al., 1987) and $\mathrm{pKD} 1$ from Kluyveromyces drosophilarum (Falcone et al., 1986). These cryptic plasmids, which we may call $2 \mu$-like plasmids, are found in high-copy-number in the host cell. All have a common structure characterized by the presence of two inverted repeats at which intramolecular recombination occurs to generate two isomeric forms of the plasmid (Hollenberg et al., 1976 ; Guérineau et al., 1976). Despite the similarity of functional organization, these plasmids share little nucleotide sequence homology. Some homology, however, has been detected at the amino acid sequence level of the plasmidencoded proteins (Murray et al., 1988).

Each of these circular plasmids has a relatively narrow host range. They can stably replicate only in their natural host and its close relatives. For example, pKD1 of $K$.

* Author for correspondence. Tel. 1698630 63; fax 169869429.

Abbreviation: IR, inverted repeat.

The nucleotide sequence data reported in this paper have been submitted to EMBL and have been assigned the accession number X56553. drosophilarum can be stably transferred to only a few other species of the genus Kluyveromyces, such as K. lactis (Bianchi et al., 1987; Chen et al., 1989).

The new plasmid, which we call $\mathrm{pKW} 1$ because it was found in a strain of Kluyveromyces waltii, has a distinct host range with respect to pKD1. We describe here the molecular and functional organization of $\mathrm{pKW}$. Various derivatives of $\mathrm{pKW} 1$ can be used as efficient vectors for gene manipulation in $K$. waltii.

\section{Methods}

Strains and media. pKW1 was isolated from Kluyveromyces waltii Kodama, CBS 6430 (type strain). The $K$. lactis (Kluyveromyces marxianus var. lactis Johannsen et van der Walt) strains were MW98$8 \mathrm{C}\left(\alpha \operatorname{uraA} \arg A \operatorname{lys} A, \mathrm{~K}^{+}, \mathrm{pKD} 1^{\circ}\right)$ and its isonuclear clone $\mathrm{MD} 2 / 1$ $\left(\mathrm{pKDl}^{+}\right)$. All the type strains of Kluyveromyces species were obtained from the Centraalbureau voor Schimmelcultures (CBS), Delft, The Netherlands. The Saccharomyces cerevisiae strain was S150-2B (Mat a ura3 leu2 trp1 his3 $\mathrm{cir}^{+}$). Complete medium (YPG) for yeast growth contained $1 \%(\mathrm{w} / \mathrm{v})$ Bacto yeast extract (Difco), $1 \%(\mathrm{w} / \mathrm{v})$ Bactopeptone (Difco) and 2\% (w/v) glucose. Minimal medium W contained $0.67 \%(\mathrm{w} / \mathrm{v})$ Yeast Nitrogen Base without amino acids (Difco) and $2 \%$ (w/v) glucose. For plating, these media were supplemented with $2.5 \%$ (w/v) Bactoagar (Difco). The Escherichia coli strains used for recombinant plasmid construction were JM83 (Vieira \& Messing, 1982) and MC1066 (Casadaban, $\mathrm{F}^{-}$lacX74 hsdR rspL galU galK $\operatorname{trpC} 9830$ leuB6 pyrF : :Tn5). Complete medium for E. coli was LB (Maniatis et al., 1982) supplemented with either ampicillin $\left(40 \mu \mathrm{g} \mathrm{ml}^{-1}\right)$ or kanamycin $\left(100 \mu \mathrm{g} \mathrm{ml}^{-1}\right)$, with or without agar $(1.5 \%, \mathrm{w} / \mathrm{v})$. 
Preparation of yeast plasmids. Small-scale crude preparations of yeast DNA (2-5 ml cultures) were obtained according to the procedure of either Cameron et al. (1977) or Sherman et al. (1983). For large-scale purification of $\mathrm{pKW} 1$, cells from 21 early stationary-phase cultures were harvested by centrifugation (13-15 $\mathrm{g}$ cells $\mathrm{l}^{-1}$ ), washed with $150 \mathrm{ml} 1 \mathrm{M}$-sorbitol/1 mM-EDTA, and resuspended in $100 \mathrm{ml}$ of $1 \mathrm{M}$ sorbitol containing $30 \mathrm{mg}$ Zymolyase 20T (Kirin Breweries Co., Tokyo, Japan). After incubation for $1 \mathrm{~h}$ at $30^{\circ} \mathrm{C}$, the protoplast suspension was mixed with $5 \mathrm{ml} 10 \%$ (w/v) SDS and $5 \mathrm{ml} 0.5 \mathrm{M}$-EDTA, pH 7.0. After vigorous swirling, the lysate was incubated at $50^{\circ} \mathrm{C}$ for $1-2 \mathrm{~h}$. Potassium acetate was added to a final concentration of $1 \mathrm{M}$, and the solution was cooled on ice for $2 \mathrm{~h}$. Precipitates were removed by centrifugation (Sorvall rotor SS34, at 15000 r.p.m. for $30 \mathrm{~min}$ ). From the supernatant, nucleic acids were precipitated at $4{ }^{\circ} \mathrm{C}$ by the addition of 2 vols $95 \%(\mathrm{v} / \mathrm{v})$ ethanol. The precipitates were collected by centrifugation, washed with $70 \%(\mathrm{v} / \mathrm{v})$ ethanol and dried under vacuum. The pellets were dissolved in $40 \mathrm{ml} 5 \times$ TE (TE is $10 \mathrm{~mm}$ Tris/ $\mathrm{HCl}, 1 \mathrm{~mm}$-EDTA, pH 8.0). After the addition of $40 \mathrm{~g} \mathrm{CsCl}$ and $4 \mathrm{ml}$ ethidum bromide ( $10 \mathrm{mg} \mathrm{ml}^{-1}$ stock), the solution was centrifuged at 60000 r.p.m. for $6 \mathrm{~h}$ (Beckman rotor $65 \mathrm{Ti}$ ). The band of supercoiled DNA beneath the chromosomal DNA was collected, and purified by a second cycle of isopycnic centrifugation. Ethidium bromide was removed by isopropanol extraction, and the plasmid DNA was dialysed against $0 \cdot 1 \times \mathrm{TE}$.

Other plasmids. The vectors used to clone $\mathrm{pK}$ W1 were YIp5 (Botstein et al., 1979) and pKan21. The latter was constructed by inserting the kanamycin resistance gene from $T n 903$ (a $1.3 \mathrm{~kb} A c c I$ fragment from the $\mathrm{Kan}^{\mathrm{R}}$ gene block, Pharmacia) into the NarI site of pUC19. The pKDl-derived plasmid, pCXJ-kan 1, contains the total pKD1 sequence (Chen et al., 1986), the URA3 gene of $S$. cerevisiae, the $\mathrm{Kan}^{\mathrm{R}}$ gene and the pUC19 sequence. The yeast $2 \mu$ plasmid was isolated from $S$. cerevisiae S150-2B, pKD1 from $K$. lactis MD2/1 (Bianchi et al., 1987), pSR1 from $Z$, rouxii CBS732, pSB1 and $\mathrm{pSB} 2$ from $Z$. bailii ATCC 8766, and pSB3 and pSB4 from $Z$. rouxii CBS 4357.

Yeast transformation. S. cerevisiae was transformed by the procedure described by Beggs (1978), and $K$. lactis by the method of Bianchi et al. (1987). The URA3 gene of $S$. cerevisiae was used to complement the ura $A$ mutation of $K$. lactis hosts. Transformation of $K$. waltii and selection of G418 resistant clones. were carried out by a protoplast procedure essentially similar to that described for $K$. lactis transformation by Chen \& Fukuhara (1988). The level of G418 was $200 \mu \mathrm{g} \mathrm{ml}^{-1}$.

Transformation of E. coli and manipulation of DNA. Published procedures were followed (e.g. Maniatis et al., 1982). For nucleotide sequencing, pKW1 DNA was subcloned into overlapping fragments in the cloning/sequencing vector pTZ18R (Pharmacia) and the dideoxy chain termination method of Sanger et al. (1977) was used.

\section{Results and Discussion}

\section{Detection of $p K W 1$}

Crude DNA was prepared from a small-scale culture of $K$. waltii CBS 6430 and analysed by agarose gel electrophoresis. In addition to the chromosomal DNA, a fast-migrating DNA was detected by ethidium bromide staining. The DNA band migrated more slowly than the reference pKD1 DNA, $4.7 \mathrm{~kb}$, of $K$. drosophilarum. Comparison of the intensity of staining suggested that the amount per cell of this DNA was roughly comparable

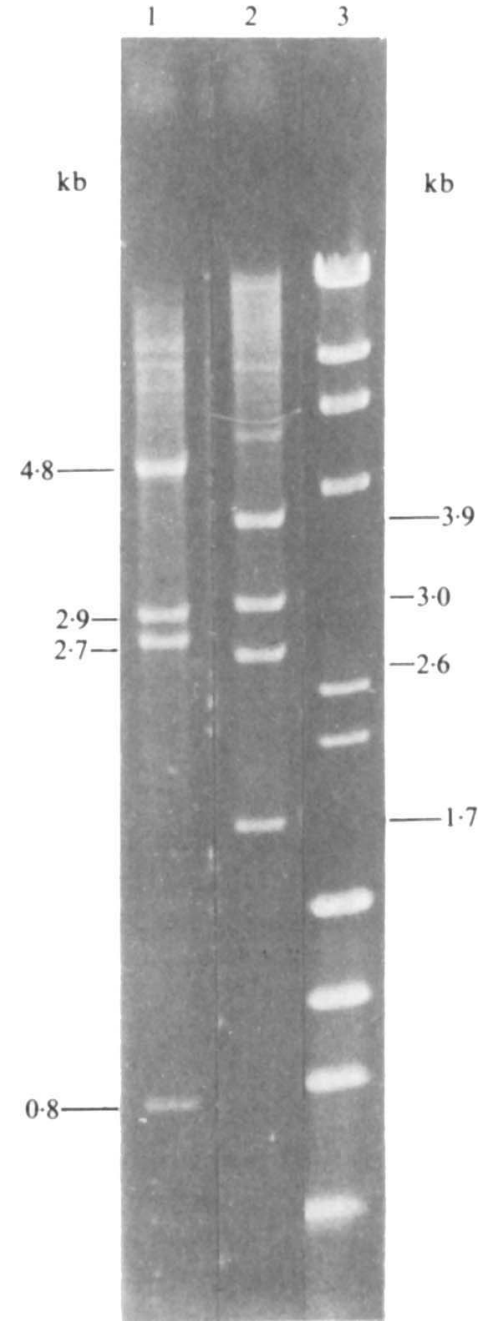

Fig. 1. Restriction digestion patterns of $\mathrm{pKW} 1$. The plasmid purified from yeast was digested by BamHI (lane 1) and by PvuII (lane 2). In each case, one sees two pairs of fragments with a constant sum $(5.6 \mathrm{~kb})$ of molecular masses $(4.8+0.8=5 \cdot 6 ; 2 \cdot 9+2 \cdot 7=5.6$, etc. $)$ The molecular mass reference (lane 3) is a mixture of $\lambda$ HindIII and $\phi$ x174 HaelII digests.

to $\mathrm{pKD} 1$ and other known circular plasmids, that is, in the order of 60 copies. The new DNA was named pKW 1 . Other strains of $K$. waltii (seven independent isolates, generously provided by $\mathrm{Dr}$ M. A. Lachance, University of West Ontario, Canada) were devoid of pKW1 or related plasmids.

Purified pKW1 DNA was analysed by digestion with various restriction enzymes. Digestion with $E c o$ RI, $S p h \mathrm{I}$, SalI, ClaI, NheI and $B g l \mathrm{II}$ gave rise to a single fragment of $5.6 \mathrm{~kb}$. Pst I or $\mathrm{XbaI}$ digests produced two fragments which again gave a total molecular mass estimate of $5.6 \mathrm{~kb}$. Bam HI or PvuII digests gave four fragments whose sum was $11.0 \mathrm{~kb}$; in both cases, the four fragments could be interpreted as two pairs of $5.6 \mathrm{~kb}$ each (Fig. 1). 

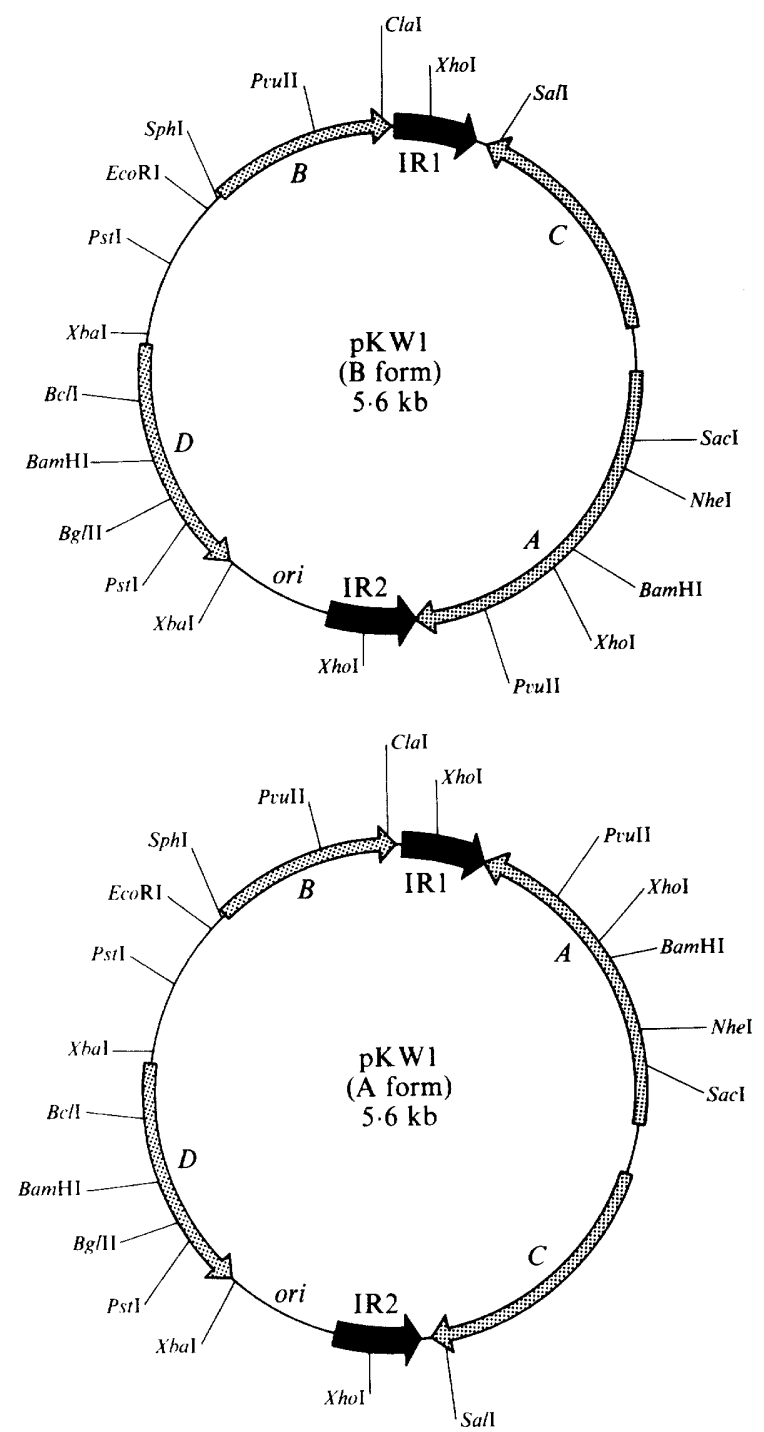

Fig. 2. Restriction maps of the $\mathrm{A}$ and $\mathrm{B}$ forms of $\mathrm{pKW} 1$. The two forms of $\mathrm{pKW} 1$ differ in the orientation of the right half of the molecule. $A, B$, $C$ and $D$ are open reading frames, IR1 and IR2 are inverted repeats.

These results suggested the presence of two isomeric forms of a circular DNA as in the case of other $2 \mu$-like plasmids.

\section{Cloning in E. coli}

The existence of two isomeric forms was confirmed by cloning pKW1 DNA into E. coli. pKW1 was opened at the unique ClaI site and cloned into the $A c c \mathrm{I}$ site of the pUC19-derived vector pKan21. Hybrid plasmids were recovered in four different combinations: the $\mathrm{A}$ and $\mathrm{B}$ forms of $\mathrm{pKW} 1$ inserted in the two possible orientations into the bacterial vector. Using these clones, the restriction maps of the A and B forms were established, as shown in Fig. 2. pKWl is composed of a pair of inverted repeat sequences of about $300 \mathrm{bp}$ each and two unique sequences of 2.6 and $2.3 \mathrm{~kb}$. These maps confirmed that internal recombination occurs at the inverted repeats to generate the two alternative forms in the yeast host.

\section{Homology of nucleotide sequence with other yeast plasmids}

To see whether $\mathrm{pKW} 1$ has any identifiable relatives among the known $2 \mu$-like plasmids, DNA sequence homology was examined by Southern hybridization under moderately stringent conditions $\left(0.6 \mathrm{M}-\mathrm{Na}^{+}\right.$, $65^{\circ} \mathrm{C}$ ), using ${ }^{32} \mathrm{P}$-labelled $\mathrm{pKW} 1$ as probe. No detectable hybrids were formed with $2 \mu$ DNA of $S$. cerevisiae, pSR 1 , $\mathrm{pSB} 3$ and $\mathrm{pSB} 4$ of $Z$. rouxii, $\mathrm{pSB} 1$ and $\mathrm{pSB} 2$ of $Z$. bailii, or pKD1 of $K$. drosophilarum.

\section{Nucleotide sequence of $p K W I$}

Fig. 3 shows the nucleotide sequence of $\mathrm{pKW} 1$. The total length is $5619 \mathrm{bp}$. The two inverted repeats, $316 \mathrm{bp}$ long, separate two unique sequences of 2643 and $2344 \mathrm{bp}$. Four open reading frames are present: $A$ (433 codons), $B$ (241 codons), $C$ (306 codons) and $D$ (289 codons). The inverted repeat sequence has a short stretch of sequence homologous with pSM1 inverted repeats as shown in Fig. 4. Although the open reading frames show little sequence similarity with other circular plasmid genes, the $A$ gene product has unambiguous amino acid sequence homology with the FLP recombinase gene of the $2 \mu$ plasmid and its equivalent in other plasmids (Fig. 5), suggesting that the $A$ gene may be involved in the interconversion of the isomeric forms of $\mathrm{pKW} 1$. While $\mathrm{pKD} 1$ of $K$. drosophilarum has three open reading frames (Chen et al., 1986), pKW1 has a fourth gene which might have a function equivalent to that of the $D$ gene of the $2 \mu$ plasmid.

\section{Localization of ARS function}

In order to identify the replication origin in the $\mathrm{pKW} 1$ sequence, we initially used a ura 3 mutant of $S$. cerevisiae as a transformation host, since no genetic markers are available in $K$. waltii. Different segments of $\mathrm{pKW} 1$ were cloned into the yeast integrative plasmid YIp5 (see Fig. 6). Each chimeric plasmid was used to transform $S$. cerevisiae and $K$. lactis $\mathrm{Ura}^{-}$hosts. Some of the $\mathrm{pKW} 1$ fragments were also cloned into pKan21 (see Methods) and used for the transformation of $K$. waltii.

The transformants in S. cerevisiae were detected by the $\mathrm{Ura}^{+}$phenotype due to the complementation of ura3 


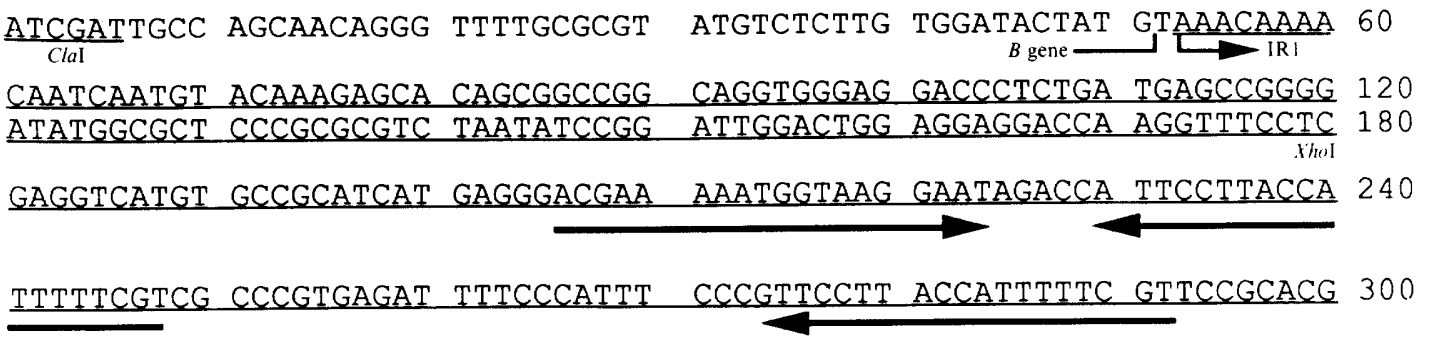
ACCCTATCAC ATTGTATATT GAAATCTACT TCCCTTCATA CCGCTTGGCC ATCGCGTAGG 360

AATGAACATA TGTAGCCCCT CTAGTTCCTC

AAGGGATCTC CTCTTGAGGC AATGTCGACG

CGTCTGTAAC ACTTCTTCTT GGTCTCCCTC TTTTGAGTTC ATCGAATAGG CGCGGGTTTT AACCGAGAGA GGTTAGAGAA GTTATTCTTT CTGGCGTTGT TTCGAAGCAC ATCAGTCCCC TTACGTTGTG CGCTTCTTCC ATGTTTTCAG CACTTCTGAC AAGTGACCAA TCTGCGAATG GAGGAACACC ACGATAGCTT GTTGTGCCCT AGCCACGTAC GTCGAGCTTT ACAGACCTGG CCTCTTCAAT CGGAAAACGG GTCAGGCTAT TCATCGTCGT GTACTTTGCG AAGTGCAGGC CCTGCTCATG TGGCTCTTTC TCCCCATTAT GCTCGGCTGG CTCTCGCAGG TACGTGGGAT CAAGATTGCA CATAATCTGC ATCAGTCTCA AGTAGGAAAC ATGCAGTTTG GAAAGGTCTA

TCTCTGTCAG TCTTTCTCTG TTTTGACCAA GGATTGCAAA AATGTTGCGA GTACTGCGTG TTTAGGAGTT CAGATGCAAC GCGTAGTGCA CATGGAACAC CAAGGATCAG TGTTCGAGGA GGAAGAATTG ATGTCTATGC TCACTAATGA TCTCCTAGCC TACATGATAA TGGCTACTGG TACCAAGTAT TCCCGACGGA TCAGGCAGAC AAGATTTGAG TACCATTTGA AGAATCCCAC

TAAACCTGTC GTGTTTGAAA TCAAGTCCAA

TGCGAAGCTC GACAAAAGGG GATCAGATTC GAAGCTTGTG CGGGAGGAAG AAATTTGGCT GGAAAAGGTG CGCAAATCAT CGCTAAGAGC TTCAATTGT TGCAGACATA GCGATCTCAG SCCAAATAAG TATGTGGGCC ACGTTGTCCG GCCGCGGTTC ATATACTTTT TCCCTGTCAA TGATTTGTTC TCGAGCACGT TTCCTTCCAA

ACAGGAATGG CAGATCGTTC GCGACGCATC GCACGCTACG GAATCTGTCT TTGCCATCTT CTTGATGAGT TCCTACTTGG CGTATACCCA TTGGTCAGCT GGGAAAGGAA CCATTGAAAG TCAAGCCGAG ATCCCAAGCG ATCTTTTCGC ATCGGGCGAT TTCGAGCTTA ACGACACCAG GGCTAGTCAA CTGGAAATCA ATCGAACCTA

TGTTTTAGGC TTTGTTCATT CCTACGCGAT AATATACAAT GTGATAGGGT CGTGCGGAAC
ATGTTGTTCT CAATCGACCC TTCCATCGTG 420 L $C$ gene TTCGTACCCT CTTCCTACGG GTCACGGGTT 480 GGCCTCTTTT ACTTGGCTGT GGCCTGGTAT 540 CTTTTACTTG AGGCCAGTCT TGAATCTCTG 600 TTAGATCATT TAACATGTCC TTGATGTCTT 660 TTGAGCGATA TCTGTCGTAA TTTGCCAGTA 720 GGGCCACATG CTTTAATGCC TGCACTAAAA 780 CAGGCTCGTT CGCCAATATC AATCTCTGTA 840 TGCAGATAGT GTTCAAGAAT AGACTGAGGT 900 TGCCAACGCC AGAAAGAAGG GCGAAGGGGT 960 CCACACGGTA CTCTCTATAT GTACTACGAG 1020 CGTGGCGATT ATAGTCAATC TGGAAAGAAT 1080 CCTCTTCAGA GTTCAGCGAG CCAGATGGCA 1140 CGGGCTCACC TCGATCCACC GTCATCTCAT 1200 ACGTCATATC GACCGCGGAA AAGGCGTCCG 1260 ACAGCTTGAG GCAGTGCATC TTGGCCTCTC 1320 $C$ gene

TTTTTCTCAA GTGTATTACA TTTGTTTCTT 1380 TTCTCGTTCA AAAACAGCGT TCGCTGAAAA 1440 AATGGAGGAT TCAAGTTGCA GTAACAATAA 1500

GCTTATCTCC AAAAATCTTA TGAGCCTGAT 1560 GAAGGAGTTC CAACGTGAAA GGTTCGCGTC 1620 TGAATTGGAA GAGAAAAAGC TCAGTACATT 1680 GGTAGAGTTC GACAGCAACA ACCAAATCGT 1740 AGAGCTCAAG GAGACGCTGG ACAAGGCCTT 1800 Sacl

AAAGAAGGTT GTCTCCATGC TGGAGCTAGC 1860

AgCGgGtgGT ACGgTAgCTA GTGAgGTCTC 1920 TCTTCTCGTG AACGTGAAGA ATACTATCCA 1980 GGAATTGACG TATATTTTGA CAGCCTCATT 2040 GAACGCAGAC CCCGCAACAT TTGAGCTGGT 2100 GGTTTTGGTG TGCGAGACCA AGACCCGAAA 2160 TACGGCCGCG GATCCTCTAG TAGCGCTTCA 2220 Bamil

AAAGAGTCGG ACGTCCGAAA GAAAGCAGGA 2280

AATCAACAAC TATGACCGGT TTGTTGGTAA 2340 GCATGGTCCC AAATCACACT TGGGCCGGCA 2400 CCATGGGGAA TGGGTCTCAC CATATGGGAA 2460 CAGCGTGGCA AGGGCCAAGT ACGCACATGT 2520 CTTTCTGTCT CAGTACTATC AGGAATCAAA 2580 CAAAGACCCA ACAAAGCTGG TACGGCACTC 2640 TGGTCCATGG AGTAGATTGG TTAACAAGGA 2700 $A$ gene GGCCAAGCGG TATGAAGGGA AGTAGATTTC 2760 GAAAAATGGT AAGGAACGGG AAATGGGAAA 2820 


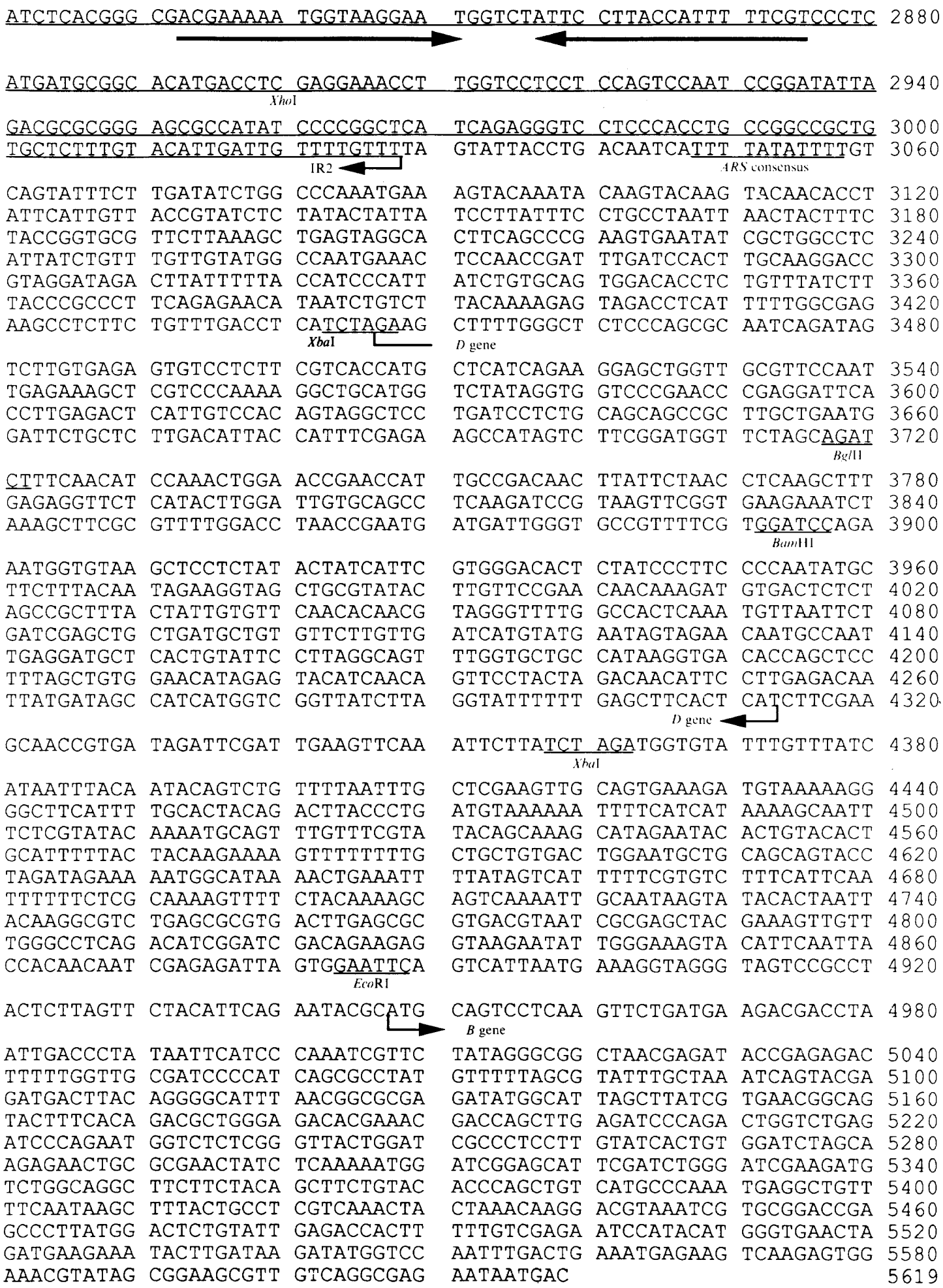

Fig. 3. Nucleotide sequence of pKW1. The sequence of form $\mathrm{B}$ is given. The numbering starts at the first base of the ClaI recognition sequence. The major restriction cleavage points used in vector construction are as follows: ClaI (nucleotide 2), XhoI (178, 2230, 2898), SalI (444), SacI (1776), NheI (1855), BamHI (2200, 3892), XbaI (3443, 4358), BglII (3717), EcoRI (4884). Inverted repeats (IRs, 316 bp) are at positions 53-368 and 2713-3028. The putative target sites of the FLP recombinase are shown by horizontal arrows in IRs. Four open reading frames are present: $A, 1454-2752$ (1299 bp); $B, 4948-51$ (723 bp); $C, 392-1309$ (918 bp, on opposite strand); $D, 3447-4313$ ( $867 \mathrm{bp}$, on opposite strand). 
pSM1 AGATGAGAGAAATGGAAGGAAT GAACC ATTCCTTTCCATTTCGCTCGCTT

$\star \star$

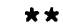

pKW 1

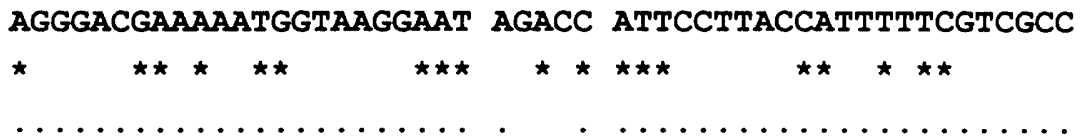

$\mathrm{pKDI}$
Fig. 4. Comparison of the putative recombination sites of pKW1, pKDl and pSMl within the IR sequences. The IRs contain a palindromic sequence which is the putative recombination site. The palindromes are marked by the dots over the sequence. Identity of bases is marked by $\hat{x}$.

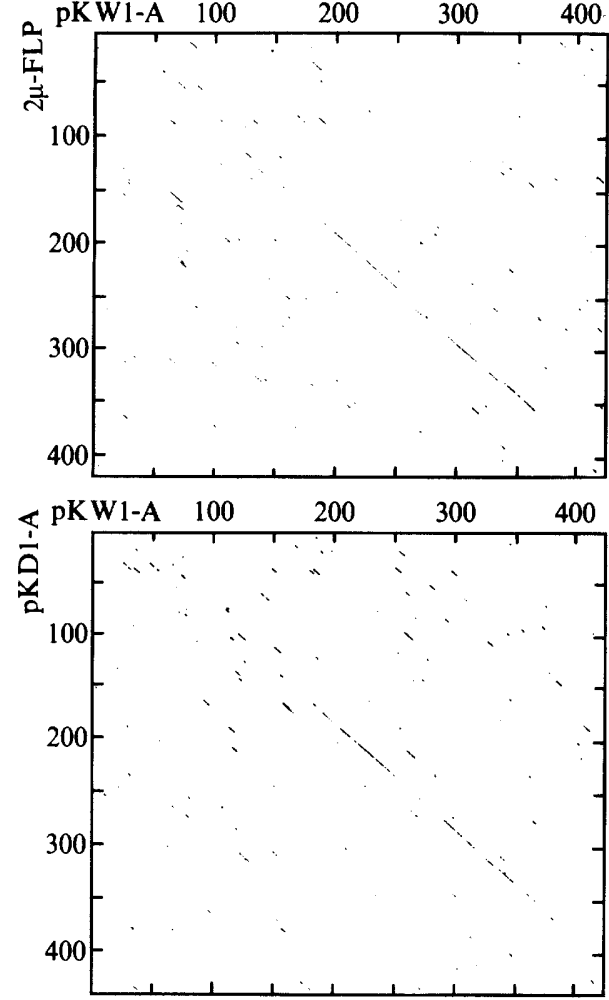

Fig. 5. Homology of the deduced amino acid sequences between pKW 1-A, $2 \mu$-FLP and pKD1-A gene products. Amino acid sequences were compared by dot-plot analysis at four matches per 10 residues. Top; pK W1-A gene vs $2 \mu$-FLP gene. Bottom; pKW1-A gene vs pKD1A gene.

mutation (Table 1). The recombinant plasmids containing a specific region near the end of one of the inverted repeats were capable of transforming $S$. cerevisiae at high frequency. This region was narrowed down to the $545 \mathrm{bp}$ XbaI-XhoI segment (nucleotides 2898-3443). An 11 bp sequence $\left(5^{\prime}\right.$ TTTTATATTTT $\left.3^{\prime}\right)$, similar to the $S$. cerevisiae $A R S$ consensus ( $5^{\prime}$ A/T TTTAT A/G TTT A/T $3^{\prime}$ ) was found within this region (nucleotides 3048-3059). Note in Table 1 that the recombinant plasmids pNEA2 and pNEB1 which gave no transformants did not contain this segment. That this segment functions as an
Table 1. Transformation of S. cerevisiae by $p K W 1$-derived plasmids

Different DNA fragments of pKW1 (see Fig. 6) were cloned in YIp5 and used to transform S. cerevisiae S150-2B (ura3 $\mathrm{cir}^{+}$). The structures of the recombinant plasmids are shown in Fig. 6. pSK 1 contains the replication origins of both $2 \mu$ and pKDl (Chen, 1987). The stability is expressed as the percentage of of Ura ${ }^{+}$cells after 10 generations of growth in liquid YPG (non-selective conditions). At least three separate transformants of each plasmid were tested. The values shown are the mean of these experiments. Data from repeated experiments generally varied less than $10 \%$.

\begin{tabular}{lccc}
\hline \hline $\begin{array}{l}\text { Recombinant } \\
\text { plasmid }\end{array}$ & $\begin{array}{c}\text { Presence of } \\
\text { XbaI-XhoI } \\
545 \text { bp segment }\end{array}$ & $\begin{array}{c}\mathrm{Ura}^{+} \text {transformants } \\
\text { per } \mu \mathrm{g} \text { DNA }\end{array}$ & $\begin{array}{c}\text { Stability } \\
(\%)\end{array}$ \\
\hline pKWS1 & + & 4400 & $0 \cdot 58$ \\
pBNA1 & + & 1200 & $0 \cdot 14$ \\
pNEA2 & - & 0 & - \\
pBNB1/A3 & + & 7600 & $0 \cdot 27$ \\
pNEB1 & - & 0 & - \\
pXXY2 & + & 4000 & $0 \cdot 12$ \\
pSK1 & + & 4500 & $60 \cdot 00$ \\
\hline \hline
\end{tabular}

$A R S$ element in the natural host $K$. waltii was confirmed by transformation of $K$. waltii (Table 2). The transformants were detected by the G418-resistant phenotype due to the $\mathrm{Kan}^{\mathrm{R}}$ gene carried by the transforming DNAs. The construct pXXK3, which contained the $545 \mathrm{bp}$ $X b a I-X h o I$ segment, showed a high frequency of transformation in $K$. waltii.

In other $2 \mu$-like plasmids, a 'stability locus', acting in cis with the $A R S$ region, is believed to play a role in the plasmid partition during cell division (Kikuchi, 1983; Jearnpipatkul et al., 1987b). Such a locus still remains to be defined in $\mathrm{pKW} 1$.

\section{Curing of $p K W 1$ from $K$. waltii}

The original host strain, CBS 6430 , which harbours pKW1 was transformed by the plasmid pKWS14 (see below). This plasmid, disrupted within the $C$ gene at the unique SalI site, is dependent on the presence of the resident $\mathrm{pKW} 1$ for its stable maintenance. G418resistant transformants were grown for 75 generations in 
(a)

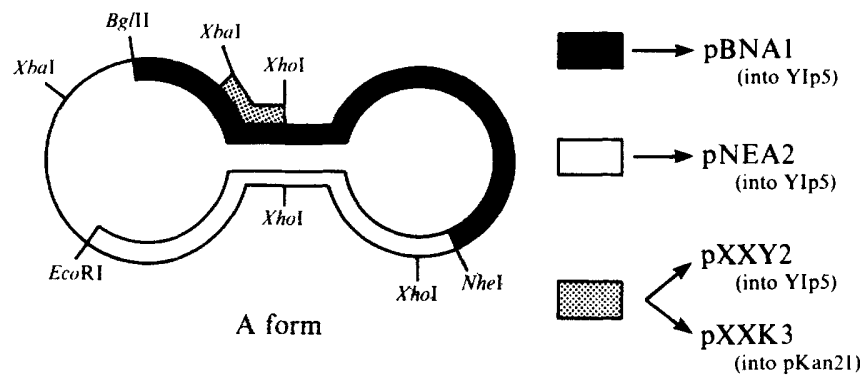

(b)

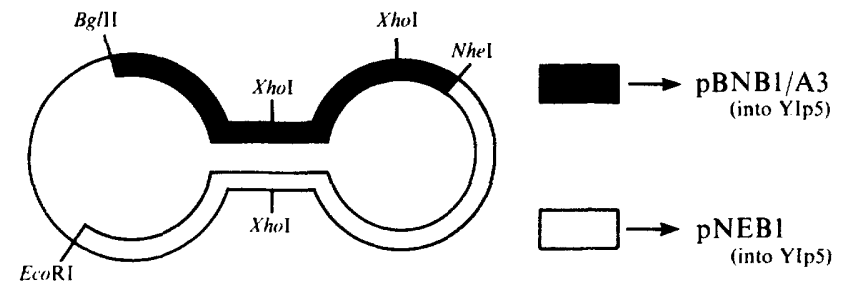

B form

$(c)$
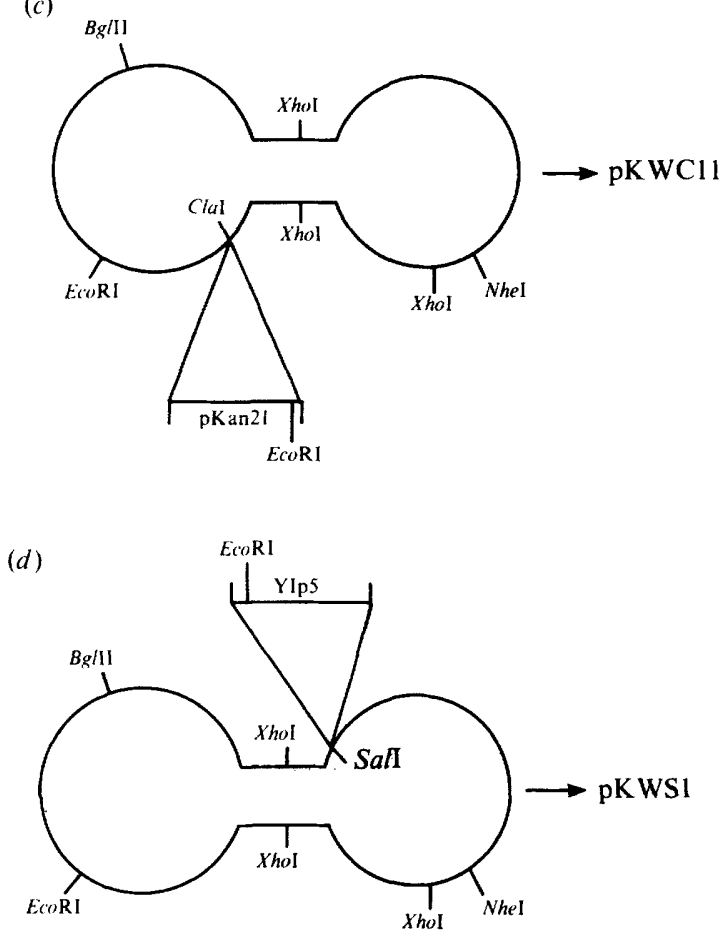

Fig. 6. Structures of recombinant molecules carrying from pKW1. (a) From the $\mathrm{A}$ form of $\mathrm{pKW} 1$, various restriction fragments were isolated as indicated by filled, open and dotted segments. They were cloned into either YIp5 or pKan21. The resulting recombinant molecules were designated pBNA1, pNEA2, pXXY2 and pXXK3, respectively, as indicated. (b) From the B form of $\mathrm{pKW}$, two restriction fragments indicated by filled and open segments were cloned into YIp5 to obtain BNB/A3 and pNEB1, respectively. (c) Structure of the plasmid $\mathrm{pKWC11}$ in which the total $\mathrm{pKW} 1$ sequence in $\mathrm{A}$ form was joined at the ClaI site to pKan21. (d) Structure of the plasmid pKWS1 in which the total pKWl sequence in A form is joined at the SalI site to YIp5.

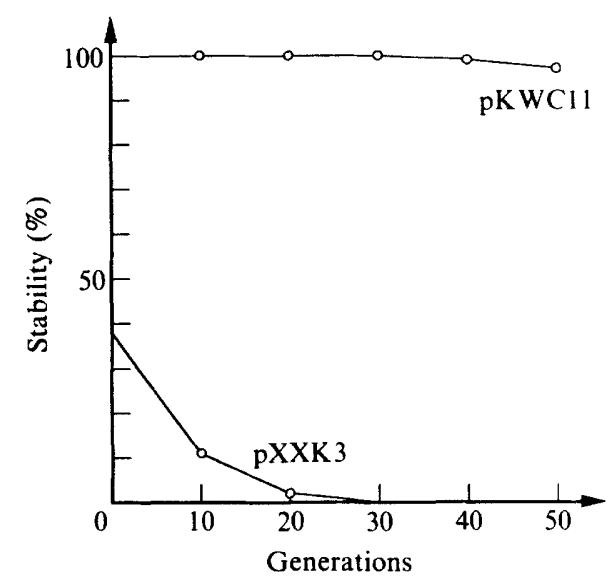

Fig. 7. Stability of pKWC1l and pXXK3 in the $K$. waltii cir strain. pKWC11 has the totality of the pKW1 plasmid sequence, while pXXK3 contains only the replication origin region of $\mathrm{pKW}$. The transformed host was $\mathrm{KW} 18$. The stability is the percentage of cells retaining the transformed phenotype (resistance to G418) after the indicated number of cell divisions under non-selective conditions (liquid YPG medium).

YPG containing G418 $\left(1 \mathrm{mg} \mathrm{ml}^{-1}\right)$. The cells were transferred to YPG (without G418) and grown for a further 10 generations. Cells were finally plated on YPG agar plates. Since pKWS14 is unstable in non-selective medium, many drug-sensitive clones were isolated, as revealed by replica plating on G418-containing plates. Among 20 such clones, five were found to be devoid of both the input vector and the resident plasmid, as verified by electrophoresis and dot-blotting hybridization of cellular DNA. One of these clones (strain KW18) was retained as a $\mathrm{cir}^{\circ}$ host and used in the transformation experiments described below.

\section{Full-sequence derivatives of $\mathrm{pKWI}$ and their stability}

pKWC11, which contained the total pKW1 sequence, also efficiently transformed $K$. waltii. In this case the transformants showed particularly high stability (Fig 7). This high stability was not due to a possible integration of the resistance gene into the chromosomes, but due to the presence of the replicating plasmid (data not shown). pKWC11 had been constructed by inserting the pKan 21 sequence at the unique $\mathrm{ClaI}$ site of $\mathrm{pKW} 1$. Therefore, the ClaI site seems to be a functionally neutral point at which insertion of a foreign sequence does not significantly affect the plasmid stability. The presence of such neutral points has previously been reported in other $2 \mu$-type plasmids: the EcoRI site of pKD1 (Bianchi et al., 1987; Chen et al., 1989), the SnaB1 or XmaIII site of the $2 \mu$ plasmid (Chinery \& Hinchliffe, 1989; Bijvoet et al., 1990 ) and at the end of the $R$ gene of pSR 1 (Jearnpipat- 
Table 2. Transformation of $K$. waltii and $K$. lactis by $p K W 1$-derived recombinant plasmids

pKWC11, pKWB11 and pKWS14 contain the entire pKW1 sequence and $\mathrm{Kan}^{\mathrm{R}}$ marker. pXXK3 has the $A R S$ segment of pKW1 as well as $\mathrm{Kan}^{\mathrm{R}}$ (see Fig. 6 for their construction) pCXJ-kanl contains the entire pKDl sequence (see Methods). The stability of transformants as defined in Table 1 is given in parentheses.

\begin{tabular}{|c|c|c|c|c|c|}
\hline \multirow{3}{*}{$\begin{array}{l}\text { Recombinant } \\
\text { plasmid }\end{array}$} & \multirow{3}{*}{$\begin{array}{l}\text { Replication } \\
\text { origin }\end{array}$} & \multicolumn{4}{|c|}{ G418 ${ }^{R}$ transformants per $\mu \mathrm{g}$ DNA } \\
\hline & & \multicolumn{2}{|c|}{ K. waltii } & \multicolumn{2}{|c|}{ K. lactis } \\
\hline & & $\left(\operatorname{cir}^{+}\right)$ & $\left(\right.$cir $\left.^{\circ}\right)$ & $\left(\mathrm{cir}^{+}\right)$ & $\left(\operatorname{cir}^{\circ}\right)$ \\
\hline pKWC11 & Total pK W1 & $\begin{array}{l}36000 \\
(98 \%)\end{array}$ & $\begin{array}{r}8000 \\
(100 \%)\end{array}$ & 0 & 0 \\
\hline pKWB 11 & Total pKW1 & $\begin{array}{l}21000 \\
(98 \%)\end{array}$ & $\begin{array}{l}10000 \\
(4.6 \%)\end{array}$ & 0 & 0 \\
\hline pKWS14 & Total pKW1 & $\begin{array}{l}10000 \\
(92 \%)\end{array}$ & $\begin{array}{r}8000 \\
(29 \%)\end{array}$ & 0 & 0 \\
\hline $\mathrm{pXXK3}$ & $\begin{array}{l}X b a \mathrm{I}-X h o \mathrm{I} 545 \text { bp } \\
\text { from pKW1 }\end{array}$ & $\begin{array}{l}35000 \\
(49 \%)\end{array}$ & $\begin{array}{l}10000 \\
(2.8 \%)\end{array}$ & 0 & 0 \\
\hline pCXJ-kanl & Total pKD1 & $\begin{array}{l}12000 \\
(94 \%)\end{array}$ & $\begin{array}{l}13000 \\
(69 \%)\end{array}$ & $\begin{array}{l}10000 \\
(62 \%)\end{array}$ & $\begin{array}{c}9700 \\
(100 \%)\end{array}$ \\
\hline
\end{tabular}

Table 3. Host range of $p K W C 11$

The species are those described by van der Walt \& Johannsen (1984). \% GC is the reported guanine-cytosine content of chromosomal DNA. Stability is defined in the legend of Table 1.

\begin{tabular}{lcccc}
\hline \hline \multicolumn{1}{c}{ Species } & Strain & $\%$ GC & $\begin{array}{c}\text { Transformation } \\
\text { frequency }\end{array}$ & $\begin{array}{c}\text { Stability } \\
(\%)\end{array}$ \\
\hline$K$. waltii & CBS 6430 & $45 \cdot 6$ & 2400 & 100 \\
$K$. thermotolerans & CBS 6340 & $46 \cdot 2$ & 4000 & 25 \\
All other species of Kluyveromyces* & $33 \cdot 1-42 \cdot 9$ & 0 & - \\
\hline \hline
\end{tabular}

* The species tested were: $K$. blattae CBS 6284; $K$. phaffi CBS 4417; $K$. polysporus CBS 2163; $K$. lodderae CBS 2757; $K$. africanus CBS 2517; $K$. aestuarii CBS 4438; $K$. delphensis CBS 2170; $K$. marxianus varieties vanudenii CBS 4372 , lactis MW98-8C, drosophilarum CBS 2105, wikenii CBS 5671, bulgaricus CBS 2762, marxianus CBS 712, dobzhanskii, CBS 2104; and $K$. wickerhamii CBS 2745.

kul et al., 1987a; Ogawa et al., 1990). These sites are in an intergenic region of the plasmid. The ClaI site of $\mathrm{pKW} 1$ is, however, within the $B$ gene, very close to C-terminus (see Fig. 2). Insertion at this site does not appear to affect the function of this gene. In contrast, two other plasmids, pKWB11 and pKWS14, obtained by insertion of pKan 21 in the $B g l I I$ site (within the $D$ gene) and the $S a l I$ site (within the $C$ gene), respectively, were highly unstable in cir $^{\circ}$ hosts (Table 2). The recombinant plasmids of the pKWC11 type are therefore the vectors of choice for the propagation and expression of foreign genes in $K$. waltii. Since the replication of $\mathrm{pKWC11}$ does not require a cir $^{+}$host, and since it contains the $\mathrm{Kan}^{\mathrm{R}}$ marker, it can be directly used for the test of host range among various yeast species (they are in most cases sensitive to G418), as shown below.

\section{Host range of $\mathrm{pKWI}$}

Although $S$. cerevisiae can be transformed by $\mathrm{pKW1-}$ derived plasmids, the transformants are quite unstable as shown in Table 1. None of the pKW1-derived plasmids were able to transform $K$. lactis (Table 2). In contrast, the pKD1-derived 'full-sequence' vector pCXJ-kanl gave stable transformants at high frequency in both $K$. lactis and $K$. waltii, confirming our previous observation (Chen et al., 1989).

In order to see the host range of $\mathrm{pKW} 1$, all the species of the genus Kluyveromyces, according to van der Walt \& Johannsen (1984), were tested for transformability by pKWC11. Table 3 summarizes the results. Only $K$. thermotolerans gave rise to transformants with a frequency comparable to that of $K$. waltii. This result may 
be correlated with the fact that $K$. thermotolerans and $K$. waltii make a distinct group within the genus, as characterized by the high GC contents of their chromosomal DNA. The stability of $K$. thermotolerans transformants was variable, very high in some clones. The absence of transformation with other species tested so far does not necessarily indicate an inability of the vector to transform them. Transformation under varied conditions remains to be examined for each species.

This work was supported in part by the Centre National de la Recherche Scientifique (AIP 6931), the High Technology Development Program of China, Rhone-Poulenc Santé and the Commission of the European Communities (BAP-0026F).

\section{References}

BEGGS, J. D. (1978). Tranformation of yeast by replicating hybrid plasmid. Nature, London 275, 104-109.

Bianchi, M. M., Falcone, C., Chen, X. J., Wesolowski-Louvel, M., Frontali, L. \& FUKUHARA, H. (1987). Transformation of the yeast Kluyveromyces lactis by new vectors derived from the $1.6 \mu \mathrm{m}$ circular plasmid pKD1. Current Genetics 12, 185-192.

Bijvoet, J. F. M., van Den Zanden, L., Brouwer, J. \& VAN De PutTe, P. (1990). Stability of 2 micron plasmid derivatives. Yeast 6, S434.

Botstein, D., Falco, S. C., Stewart, S. E., Brennan, M., Scherer, S., Stincomb, D. T., Struhl, K. \& Davis, R. W. (1979). Sterile host yeast (SHY): a eukaryotic system of biological containment for recombinant DNA experiments. Gene 8, 17-24.

Cameron, J. R., Philipssen, P. \& Davies, R. V. (1977). Analysis of chromosomal integration and deletions of yeast plasmids. Nucleic Acids Research 4, 1429-1448.

CHEN, X. J. (1987). Etude du plasmide pKDI et développement de systèmes d'expression de gènes chez la levure Kluyveromyces lactis. $\mathrm{PhD}$ thesis. University of Paris XI, France.

Chen, X. J. \& Fuxuhara, H. (1988). A gene fusion system using the aminoglycoside 3'-phosphotransferase gene of the kanamycinresistance transposon $\mathrm{Tn} 903$ : use in the yeasts Kluyveromyces lactis and Saccharomyces cerevisiae. Gene 69, 181-192.

Chen, X. J., Saliola, M., Falcone, C., Bianchi, M. M. \& Fukuhara, H. (1986). Sequence organization of the circular plasmid pKD1 from the yeast Kluyveromyces drosophilarum. Nucleic Acids Research 14, $4471-4481$

Chen, X. J., Bianchi, M. M., Suda, K. \& Fukuhara, H. (1989). The host range of the pKD1-derived plasmids in yeast. Current Genetics 16, 95-98.

Chinery, S. A. \& Hinchliffe, E. (1989). A novel class of vector for yeast transformation. Current Genetics 16, 21-25.
Falcone, C., Saliola, M., Chen, X. J., Frontali, L. \& Fukuhara, H. (1986). Analysis of a $1.6 \mu \mathrm{m}$ circular plasmid from the yeast Kluyveromyces drosophilarum: structure and molecular dimorphism. Plasmid 15, 248-252.

Guérineau, M., Grandchamp, C. \& Slonimski, P. P. (1976). Circular DNA of a yeast episome with two inverted repeats: structural analysis by a restriction enzyme and electron microscopy. Proceedings of the National Academy of Sciences of the United States of America 73, 3030-3034.

HollenberG, C. P., Degelmann, A., Kustermann-Kuhn, B. \& ROYER, H. D. (1976). Characterization of a $2 \mu \mathrm{m}$ DNA of Saccharomyces cerevisiae by restriction fragment analysis and integration in an Escherichia coli plasmid. Proceedings of the National Academy of Sciences of the United States of America 73, 2072-2076.

JearnPIPATKUL, A., ARAKI, H. \& Oshima, Y. (1987a). Factors encoded by and affecting the holding stability of yeast plasmid pSR1. Molecular and General Genetics 206, 88-94.

Jearnpipatkul, A., Hutacharoen, R., ARaki, H. \& Oshima, Y. $(1987 \mathrm{~b})$. A cis-acting locus for stable propagation of yeast plasmid pSR1. Molecular and General Genetics 207, 355-360.

KIKUCHI, Y. (1983). Yeast plasmid requires a cis-acting locus and two plasmid proteins for its stable maintenance. Cell 35, 487-493.

Maniatis, T., Fritsch, E. F. \& SambrooK, J. (1982). Molecular Cloning, a Laboratory Manual. Cold Spring Harbor, NY : Cold Spring Harbor Laboratory.

Murray, J. A. H., Cesareni, G. \& Argos, P. (1988). Unexpected divergence and molecular coevolution in yeast plasmids. Journal of Molecular Biology 200, 601-607.

Ogawa, Y., Tatsumi, H., Murakami, S., Ishida, Y., Murakami, K., Masaki, A., Kawabe, H., Arimura, H., Nakano, E., Motai, H. \& TOH-E, A. (1990). Secretion of Aspergillus orgazae alkaline protease in an osmophilic yeast, Zygosaccharomyces rouxii. Agricultural and Biological Chemistry 54, 2521-2529.

SANGeR, F., NiCKLeN, S. \& Coulson, A. R. (1977). DNA sequencing with chain-terminating inhibitors. Proceedings of the National Academy of Sciences of the United States of America 74, 5463-5467.

Sherman, F., Fink, G. R. \& Hicks, J. B. (1983) Methods in Yeast Genetics. Cold Spring Harbor, NY: Cold Spring Harbor Laboratory.

TOH-E, A., TADA, S. \& Oshima, Y. (1982). 2- $\mu \mathrm{m}$ DNA-like plasmids in the osmophilic haploid yeast Saccharomyces rouxii. Journal of Bacteriology 151, 1380-1390.

Toh-e, A., Araki, H., Utatsu, I. \& Oshima, Y. (1984). Plasmids resembling $2-\mu \mathrm{m}$ DNA in the osmotolerant yeasts Saccharomyces bailii and Saccharomyces bisporus. Journal of General Microbiology 130, 2527-2534.

Utatsu, I., Sakamoto, S., Imura, T. \& Toh-E, A. (1987). Yeast plasmids resembling $2-\mu \mathrm{m}$ DNA: regional similarities and diversities at the molecular level. Journal of Bacteriology 169, 5537-5545.

Vieira, J. \& Messing, J. (1982). The pUC plasmids, a M13mp7derived system for insertion mutagenesis and sequencing with synthetic universal primers. Gene 19, 259-268.

VAN DER WaLT, J. P. \& Johannsen, E. (1984). The Yeasts, a Taxonomic Study, 3rd edn, pp. 224-265. Edited by N. J. W. Kreger van-Rij. Amsterdam: Elsevier Science Publishers. 